\title{
Microvascular filtration in subjects with connective tissue disorders
}

\author{
J. C. W. EDWARDS AND M. L. SNAITH \\ From the Department of Rheumatology, University College Hospital, London WC1
}

SUMmARY A simple non-invasive method for studying microvascular filtration in the nonarticular tissues of the forearm is described. Rates of filtration under a standard hydrostatic pressure were measured in 20 normal female subjects and 44 female subjects with connective tissue disorders. An increased mean filtration rate was found in 14 subjects with rheumatoid arthritis. In 20 subjects with systemic lupus erythematosus and 10 subjects with scleroderma no such generalised increase in filtration rates was seen, but isolated cases had very high filtration rates, suggesting a more heterogeneous physiological disturbance. Increased filtration was not associated with the presence of oedema. This confirms doubts raised by other workers about the importance of filtration in the genesis of clinical oedema.

In 1971 Jayson and Barks showed that people with rheumatoid arthritis tended to have an increased coefficient of capillary filtration in the non-articular tissues of the forearm. ${ }^{1}$ The mechanism of this physiological change is unclear, but it could relate to increased microvascular hydraulic conductance or an increased functional surface area. Subsequently, using a different approach, Marks $e t$ al. showed that people with a variety of connective tissue disorders including systemic lupus erythematosus and systemic sclerosis had increased transcapillary escape rates for radiolabelled albumin. ${ }^{2}$ This was taken as further evidence for abnormal capillary filtration in people with connective tissue problems. However, since albumin escape may occur predominantly in the liver, the relationship between these findings and those of Jayson and Barks is doubtful.

Prompted by these studies we have measured microvascular filtration rates in subjects with a range of connective tissue disorders similar to those studied by Marks et al. using a technique comparable to that of Jayson and Barks. The abnormalities described in albumin escape rates were gross. If abnormalities of a similar degree could be measured by a simple non-invasive technique, they might be expected to be of considerable clinical value, since at present we have no other objective tests of microvascular physiology in connective tissue disorders.

Accepted for publication 13 February 1984.

Correspondence to J. C. W. Edwards, Department of Rheumatology, University College Hospital, Grafton Way, London WC1.

\section{Material and method}

\section{METHOD}

The rate of lymph production by filtration under a fixed venous occlusion pressure was estimated from the increase in circumference of the forearm. This was measured by a simple fibreglass thread gauge (Fig. 1). Changes in volume $\mathrm{V}$ were calculated from changes in circumference $\mathrm{C}$ by the formula:

$$
\frac{\mathrm{dV}}{\mathrm{V}}=\frac{2 \mathrm{dC}}{\mathrm{C}} .
$$

This is derived from the equation;

$$
V=f\left(C^{2}\right) \text {, }
$$

where $f$ is a constant linear function if the crosssectional shape is constant. For small $\mathrm{dC}$ this approximates to;

$$
V+d V=f\left(C^{2}+2 C d C\right)
$$

Combining the two equations leads to:

$$
\frac{\mathrm{dV}}{\mathrm{V}}=\frac{2 \mathrm{dC}}{\mathrm{C}}
$$

The thread gauge consisted of two-ply fibreglass (International Yacht Equipment). Glass was chosen because of its low friction on skin, its high Young's modulus, and its freedom from hysteresis. Two-ply thread was found empirically to have the lowest friction on skin. The great majority of glass fibres 


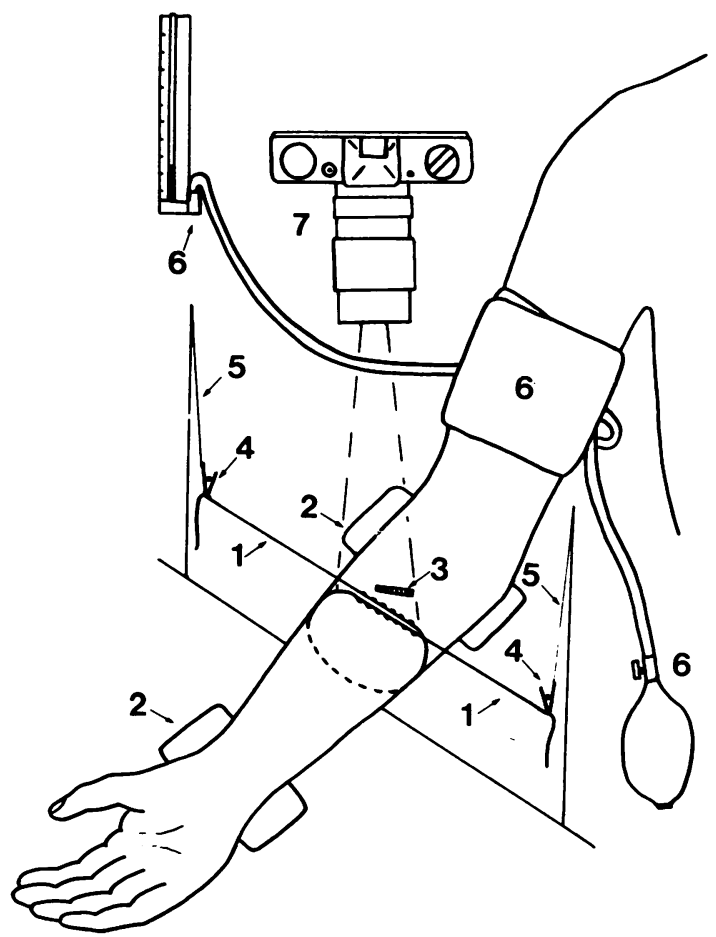

Fig. 1 Method of measuring filtration. (1) Thread gauge. (2) Arm supports. (3) Centimetre scale. (4) Crocodile clips. (5) Suspension frame. (6) Sphygmomanometer cuff.

(7) $35 \mathrm{~mm}$ Camera with 1:1 macro lens.

ran the length of the thread. No unravelling of the thread occurred, as judged by the absence of any twisting of the ends on serial photographs. The thread was marked at intervals with black spirit ink. Marks were allowed to vary, since this allowed each mark to be identified individually (Fig. 2). Mercury strain gauge and waterbath plethysmographs were found unsuitable for estimating filtration in subjects with connective tissue disorders, since both caused visible indentation of the tissues.

The subject lay on a couch with the upper trunk at $30^{\circ}$ to the horizontal. The right arm was abducted and the elbow and wrist supported, so that the forearm lay horizontally at heart level. A sphygmomanometer cuff was wrapped around the upper arm. The thread gauge was passed once round the forearm at a point one-third of the way from the olecranon to the ulnar styloid. The ends of the thread leading out sideways from the upper surface of the forearm were held by crocodile clips weighing $1.0 \mathrm{~g}$ each. The clips were suspended from a frame in such a way that $10 \%$ of their weight was converted to thread tension $(0 \cdot 1 \mathrm{~g}$ weight $)$. This was

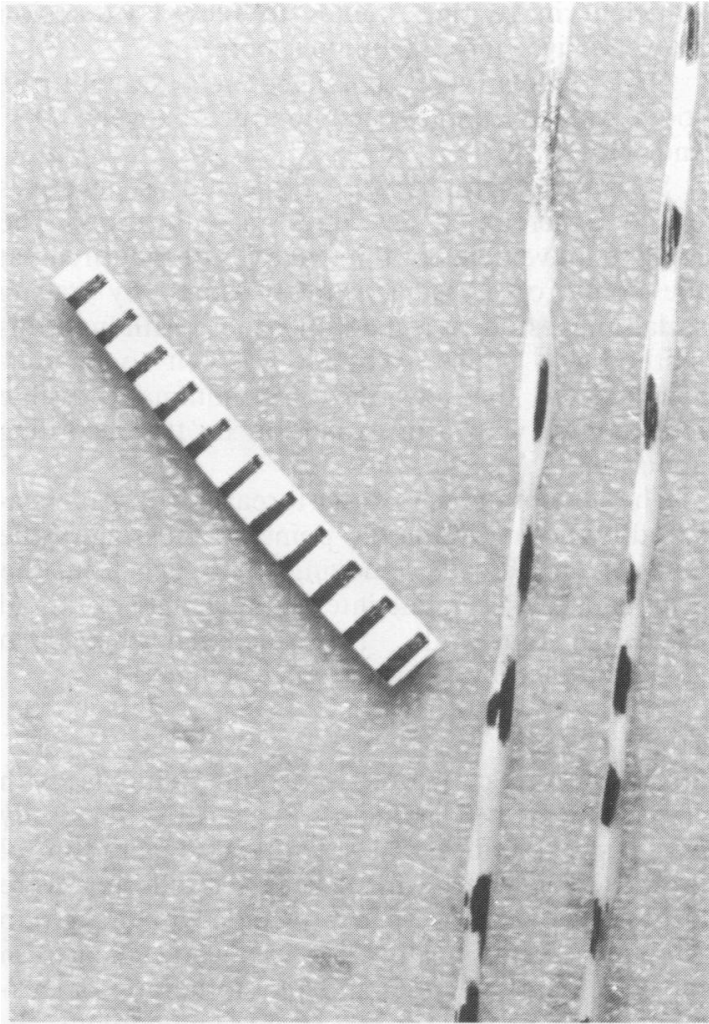

Fig. 2 Thread gauge with centimetre scale. Although the spirit ink markings on the thread appear crude, they allow reliable measurement to 30 um of arm expansion.

found to be the minimum tension to overcome inherent curves in the thread and to hold the hairs on the arm opposed to the skin. Increasing tension to $1 \mathrm{~g}$ weight led to tissue indentation after 10 minutes in some cases and was therefore unacceptable.

The thread gauge was left under tension for at least three minutes before recordings were made. A centimetre scale was placed next to the thread for recording purposes. The positions of the two thread ends at the points where they crossed on the upper surface of the forearm were recorded at 30 -second intervals during the experiment by serial photographs taken with a macro lens. The sphygmomanometer cuff was inflated to $60 \mathrm{mmHg}$ pressure and maintained at that pressure for 10 minutes. Rapid expansion of the forearm due to venous filling occurred during the first three to five minutes. After this a slower linear expansion was seen, representing lymph production. This did not change between five and 15 minutes in pilot studies, and it was found 
sufficient in routine studies to record expansion between five and 10 minutes only.

Experiments were conducted in a draught-free room with an ambient temperature between $21^{\circ} \mathrm{C}$ and $24^{\circ} \mathrm{C}$.

Serial photographs were projected as negatives on to a screen at 20 times magnification. The relative movements of the two ends of the thread at the points of crossing were measured by tracing serial images on to a sheet of paper. Although this method was cumbersome, it was felt to be outweighed by the advantage of minimal possible interference with arm expansion by the recording apparatus.

The circumference of the forearm (C) was measured by noting the initial points of crossing of the ends of the thread, removing the gauge from the arm, and measuring the intervening length of thread against a rigid rule. The fractional change in circumference $\mathrm{dC} / \mathrm{C}$ was then calculated.

\section{SUBJECTS}

Since the great majority of our patients with connective tissue disorders were female, the study was restricted to females, with a female control group. Two males with severe scleroderma were also studied, but were not included in the group analysis. Twenty healthy controls were taken from the rheumatology staff and physiotherapy department. Patients were taken from rheumatology clinics and were suffering from either rheumatoid arthritis, systemic lupus erythematosus (SLE), or scleroderma. Two subjects with intermittent idiopathic leg oedema were also studied.

Normal subjects were aged $22-57$ years, mean 31 years. None had oedema.

Rheumatoid arthritis subjects fulfilled the American Rheumatism Association criteria for definite or classical rheumatoid arthritis. Two patients also fulfilled the criteria for SLE. Ages ranged from 36 to 70 years, mean 54 years. The presence or absence of dependent oedema was recorded. Serum albumin levels ranged from 36 to $43 \mathrm{~g} / \mathrm{l}$, mean $39 \mathrm{~g} / \mathrm{l}$ (all within normal limits).

Subjects with SLE fulfilled the American Rheumatism Association preliminary criteria. Two subjects also fulfilled the criteria for rheumatoid arthritis. Ages ranged from 19 to 63 years, mean 38 years. Albumin levels ranged from 24 to $48 \mathrm{~g} / \mathrm{l}$, mean $40 \mathrm{~g} / \mathrm{l}$. Three subjects with albumin levels of 24,26 , and $33 \mathrm{~g} / \mathrm{l}$ had significant proteinuria of 10 , 18 , and $9 \mathrm{~g} / 24 \mathrm{~h}$ respectively. The presence or absence of oedema was recorded.

Subjects with scleroderma were selected solely on the basis of a sclerodermatous appearance of the skin other than isolated morphoea. All subjects proved to have Raynaud's phenomenon, six had abnormalities of gut motility on cineradiography, three had ischaemic autoamputation of digits, three had a symptomatic restrictive lung defect, and one had coexistent squamous carcinoma, probably of oesophageal origin. Ages ranged from 24 to 60 years, mean 46 years. Serum albumin levels ranged from 39 to $49 \mathrm{~g} / \mathrm{l}$, mean $43 \mathrm{~g} / \mathrm{l}$. None had significant proteinuria or other evidence of renal impairment.

\section{Results}

The method described was found to give recordings of arm expansion similar to those of other workers in time course and pattern (see Fig. 3). There was no relation between filtration rate and age or arm size.

Filtration rates for 20 normal subjects ranged from 0.096 to $0.270 \mathrm{ml} / 100 \mathrm{ml} / \mathrm{min}$ at $60 \mathrm{mmHg}$

\section{- THREAD GAUGe \\ - WATER BATH (FROM JAYSON)}

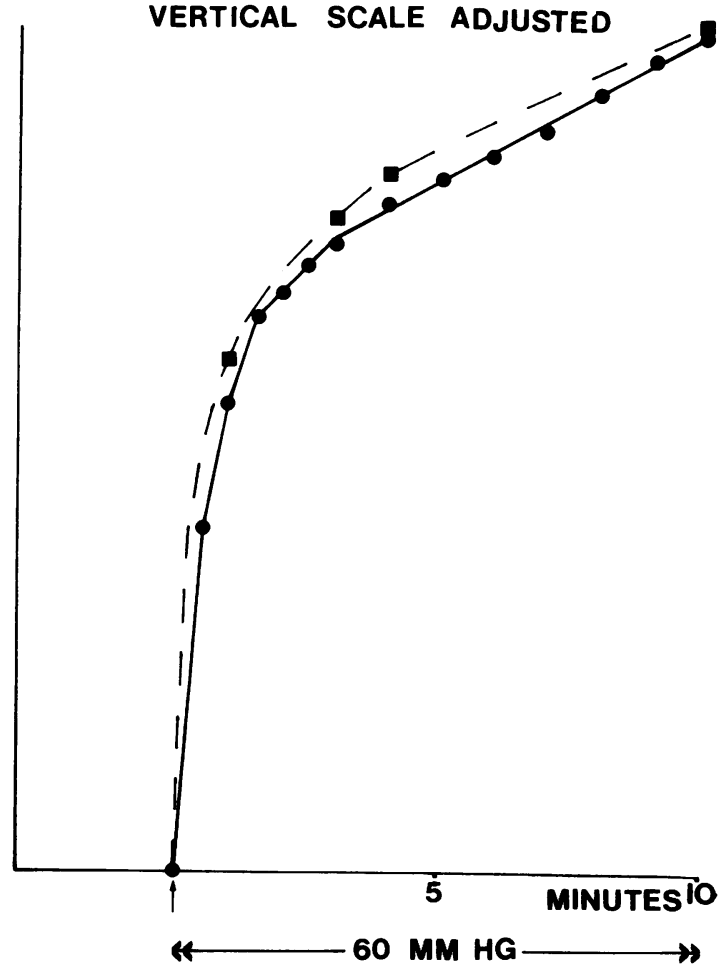

Fig. 3 Patterns of arm expansion under a venous occlusion pressure of $60 \mathrm{mmHg}$, for waterbath and thread gauge plethysmographs. With an adjusted vertical scale a similar rapid venous filling phase is seen, followed by a slow filtration phase. 
venous pressure, mean $0.172 \mathrm{ml} / 100 \mathrm{ml} / \mathrm{min}$ and an approximately normal distribution. (SI conversion: $\mathrm{ml} / 100 \mathrm{ml} \times 10=\mathrm{ml} / \mathrm{l}$.)

Filtration rates for 14 patients with rheumatoid arthritis ranged from $0 \cdot 126$ to $0 \cdot 318 \mathrm{ml} / 100 \mathrm{ml} / \mathrm{min}$, mean $0.230 \mathrm{ml} / 100 \mathrm{ml} / \mathrm{min}$. This was significantly greater than normal $(\mathrm{p}<0 \cdot 01)$. Filtration rates did not correlate with the presence or absence of oedema (Fig. 4).

In 20 patients with SLE the filtration rates ranged from 0.138 to $0.396 \mathrm{ml} / 100 \mathrm{ml} / \mathrm{min}$, mean 0.204 $\mathrm{ml} / 100 \mathrm{ml} / \mathrm{min}$. The majority of values fell between normal limits. However, the only two patients who were acutely ill at the time of recording had values at or above the upper limit of the normal range. A third patient, in clinical remission, also had a particularly high filtration rate, well outside the normal range (Fig. 5). Only two patients in this group had dependent oedema at the time of recording. Their filtration rates were well within the normal range despite severe hypoalbuminaemia in both cases (24 and $26 \mathrm{~g} / \mathrm{l})$.

In 10 female patients with scleroderma the filtration rates ranged from 0.072 to $0.408 \mathrm{ml} / 100$ $\mathrm{ml} / \mathrm{min}$. The majority of values were within or slightly below the normal range, but a single patient with Raynaud's phenomenon and very early diffuse

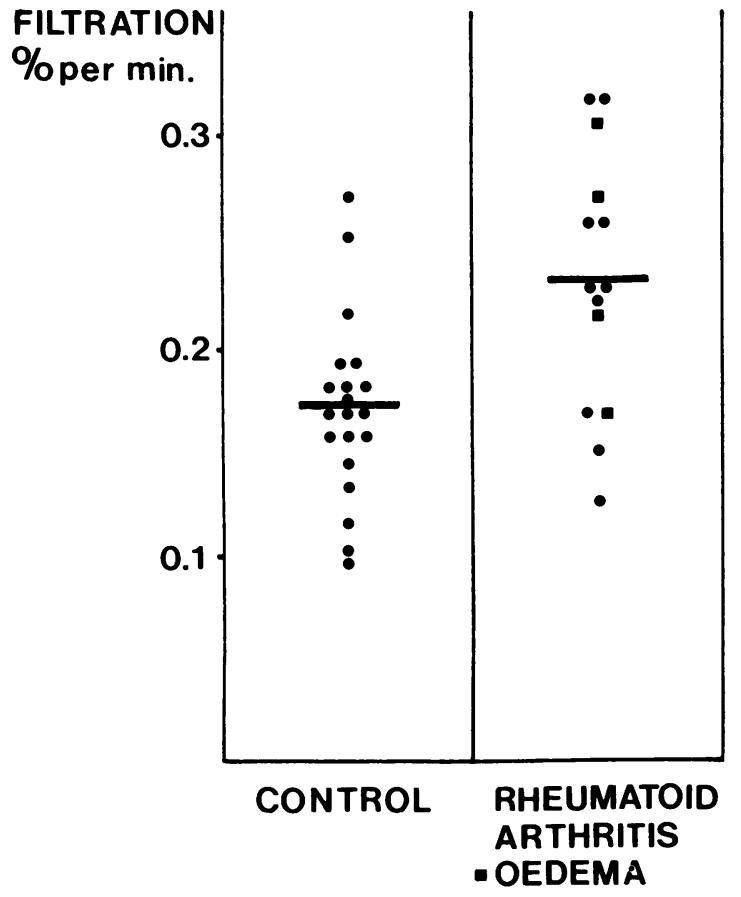

Fig. 4 Filtration rates in subjects with rheumatoid arthritis.

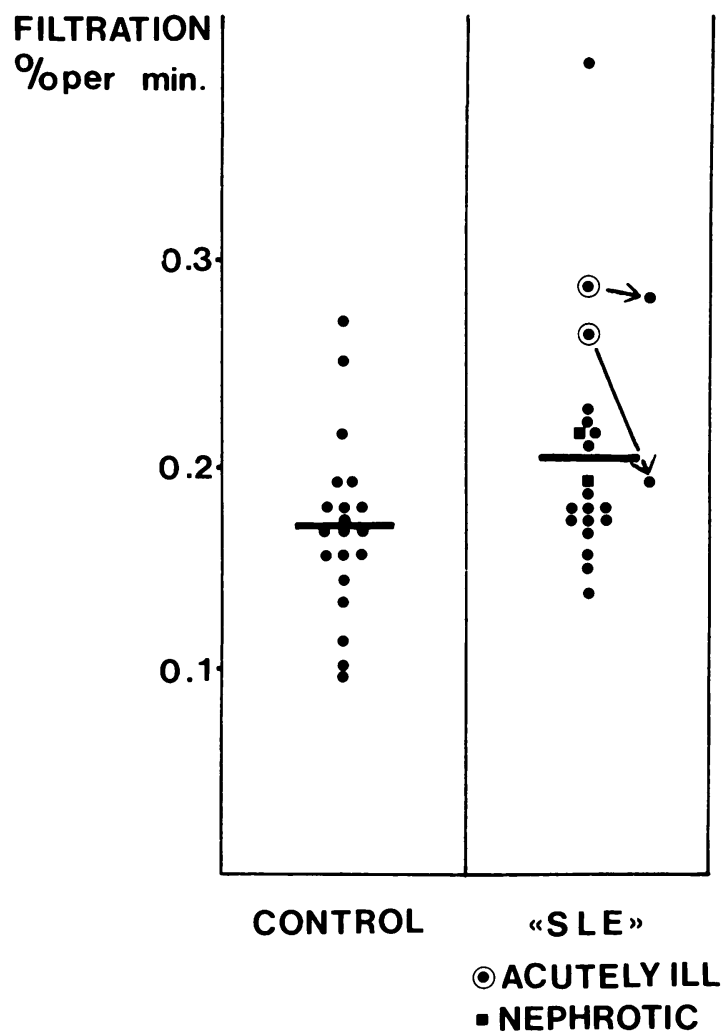

Fig. 5 Filtration rates in subjects with systemic lupus erythematosus. The arrows indicate changes following high-dose steroid.

scleroderma of the trunk had the highest value recorded in all groups $(0.408 \mathrm{ml} / 100 \mathrm{ml} / \mathrm{min})$ (Fig. $6)$.

Two patients with idiopathic intermittent leg oedema had filtration rates in the normal range $(0 \cdot 136$ and $0 \cdot 160 \mathrm{ml} / 100 \mathrm{ml} / \mathrm{min})$.

\section{Discussion}

The analysis of microvascular filtration in this study differs in one major respect from that used by Jayson and Barks. ${ }^{1}$ These authors studied filtration at two hydrostatic pressures and derived a coefficient of capillary filtration. In theory their results should reflect only changes in the vessel wall rather than changes due to altered oncotic gradients. Unfortunately there is evidence that the coefficient of capillary filtration is not constant under the conditions of this type of experiment. ${ }^{3}$ Moreover, the coefficient of filtration appears to be significantly affected by the oncotic environment. ${ }^{3-5} \mathrm{~A}$ 


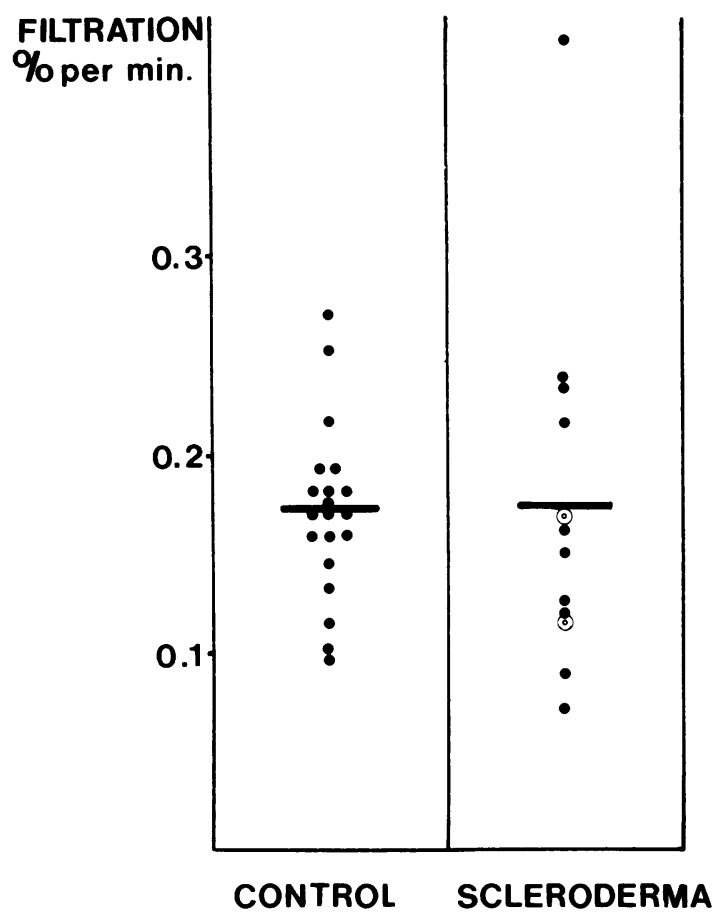

๑MALE

Fig. 6 Filtration rates in subjects with scleroderma.

valid interpretation of the mechanisms of filtration abnormalities probably requires the analysis of a number of variables in a way impracticable in a routine outpatient setting. We have instead used a single hydrostatic pressure for studying filtration simply to assess the presence or absence of a change in filtration rate without attempting to establish the precise mechanism.

We have confirmed the presence of increased filtration under hydrostatic pressure in subjects with rheumatoid arthritis. In view of the fact that these subjects had normal serum albumin levels it seems likely that we have observed the same phenomenon reported by Jayson and Barks, though an oncotic disturbance cannot entirely be excluded. In the other groups we have not found the generalised increase in filtration that might be predicted from the observations of Marks et al. ${ }^{2}$ Only isolated subjects had abnormal rates. Although the populations may not be strictly comparable, this suggests that increased albumin escape is not necessarily associated with increased microvascular filtration in the limbs.

The most striking finding of the study. which was totally unexpected, was the total lack of correlation between increased filtration rates and oedema. Two patients with no oedema had filtration rates under the test conditions double those of two other patients with marked leg oedema associated with florid nephrotic syndrome. Regardless of the reason for increased filtration, if leg oedema is to be explained on the basis of increased filtration, such an increase should be apparent if an appropriate hydrostatic pressure is applied to the veins in the arm. Venous pressure in the legs is very variable, and it is difficult to know what a comparable venous occlusion pressure would be for the arm. If 60 $\mathrm{mmHg}$, as used in this study, is approximately comparable, then the results of this study cast serious doubt on the assumption that filtration is the chief determinant of oedema in conditions such as nephrotic syndrome.

Such doubts have previously been voiced by many authors reviewing the topic. The work of Mees $e t$ $a l^{6}$ is particularly relevant, as has recently been discussed by Cameron. ${ }^{7}$ One explanation of normal filtration in nephrotic subjects would be an increased tissue pressure. This seems unlikely in the present study, since none of the patients had noticeable oedema or change in tissue laxity in the forearm where measurements were taken.

An alternative explanation for clinical oedema in this context is that the limiting factor is total fluid clearance from the limbs, and that how much returns in the veins and how much in the lymphatics is relatively unimportant. Raised central venous pressure, muscle pump failure (from weakness, pain, or failure of appreciation of tissue turgor for neurological reasons) and increased endothelial permeability will inhibit fluid clearance by both venous and lymphatic channels. Further study of filtration is required in a wider clinical context, since it seems that mechanisms of clinical oedema are still far from clear.

\section{References}

1 Jayson M I V, Barks J S. Oedema in rheumatoid arthritis. $\mathrm{Br}$ Med $J$ 1971; ii: 555-7.

2 Marks J, Birkett D A. Shuster S. Capillary permeability in patients with collagen vascular disease. Br Med J 1972; i: 782-4.

3 Taylor A E. Capillary fluid filtration. Circ Res 1981; 49: 557-76.

4 Renkin E M, Bell D R, Kramer G C. Determinants of lymph flow and composition. In: Kovach A G B, Hamar J, Szabo L, eds. Advances in physiological sciences: cardiovascular physiology. Budapest: Akademiai Kindo, 1981; 237-40.

5 Kramer G C, Harms B A, Gunther R A, Renkin E M, Demling $\mathrm{R} \mathrm{H}$. The effects of hypoproteinaemia on blood to lymph fluid transport in sheep lung. Circ Res 1981; 49: 1173-80.

6 Mees E J D, Roos J C, Boer P, Yoe O H, Simatupang T A. Observations on edema formation in the nephrotic syndrome in adults with mininal lesions. Am J Med 1979; 67: 378-84

7 Cameron J S. Proteinuria and the nephrotic syndrome. In: Weatherall D J, Ledingham J G G, Warrell D A, eds. Oxford textbook of medicine. Oxford University Press, 1983: 1852-62. 